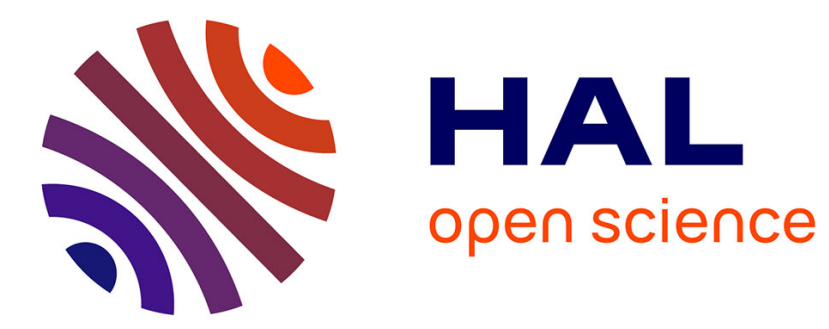

\title{
Mobility Degradation Influence on the SOI MOSFET Channel Length Extraction at $77 \mathrm{~K}$
}

\author{
A. Nicolett, J. Martino, E. Simoen, C. Claeys
}

\section{To cite this version:}

A. Nicolett, J. Martino, E. Simoen, C. Claeys. Mobility Degradation Influence on the SOI MOSFET Channel Length Extraction at 77 K. Journal de Physique IV Proceedings, 1996, 06 (C3), pp.C3-55-

C3-59. 10.1051/jp4:1996308 . jpa-00254226

\section{HAL Id: jpa-00254226 https://hal.science/jpa-00254226}

Submitted on 1 Jan 1996

HAL is a multi-disciplinary open access archive for the deposit and dissemination of scientific research documents, whether they are published or not. The documents may come from teaching and research institutions in France or abroad, or from public or private research centers.
L'archive ouverte pluridisciplinaire HAL, est destinée au dépôt et à la diffusion de documents scientifiques de niveau recherche, publiés ou non, émanant des établissements d'enseignement et de recherche français ou étrangers, des laboratoires publics ou privés. 


\title{
Mobility Degradation Influence on the SOI MOSFET Channel Length Extraction at $77 \mathrm{~K}$
}

\author{
A.S. Nicolett*, J.A. Martino, E. Simoen** and C. Claeys** \\ Laboratório de Sistemas Integráveis, Universidade de São Paulo, Brazil \\ * Faculdade de Tecnologia de São Paulo, Brazil \\ ** IMEC, Kapeldreef 75, 3001 Leuven, Belgium
}

\begin{abstract}
This work studies the influence of mobility degradation on the effective channel length $\mathrm{L}_{\text {eff }}\left(\mathrm{L}_{\mathrm{eff}}=\mathrm{L}_{\mathrm{m}}-\Delta \mathrm{L}\right.$ ) extraction in submicron fully depleted SOI MOSFETs at $77 \mathrm{~K}$. Second-order effects can cause mobility degradation, mainly at $77 \mathrm{~K}$, and if standard techniques have been used, negative values of $\Delta \mathrm{L}$ can be obtained. It will be shown that this result can be caused by a length-dependent mobility degradation factor.
\end{abstract}

\section{INTRODUCTION}

Effective channel length $L_{\text {eff }}$ and effective mobility $\mu_{\text {eff }}$ are important parameters for process control and device performance. Several techniques $[1-4]$ have already been developed to extract $L_{\text {eff }}$ and typically this parameter is calculated from $I_{d s}-V_{g s}$ data on transistors with different channel lengths $L_{m}$ (L-array). $\mathrm{L}_{\text {eff }}\left(\mathrm{L}_{\mathrm{m}}-\Delta \mathrm{L}\right)$ is extracted with electrical techniques and reflects an electrical dimension, not necessarily a physical dimension [2]. The channel ends where the gate-induced carrier density equals the doping density in the LDD regions. This implies that an increment of the charge in the channel by raising the gate overdrive voltage $\left(\mathrm{V}_{\mathrm{gs}}-\mathrm{V}_{\mathrm{th}}\right)$ will result in an extension of the channel into the LDD regions [2].

The different extraction techniques assume that the mobility degradation factor is constant for all L-array transistors. However, when the dimensions of the devices are scaled down, second-order effects appear, such as increase of the source-drain resistance [5], and a variation of the threshold voltage due to short channel [6] and hot electron effects [7]. These second-order effects can cause mobility degradation, especially at $77 \mathrm{~K}$ [8]. Consequently, using the standard electrical extraction techniques, negative values for $\Delta \mathrm{L}$ can been obtained. In this work the effect of mobility degradation on the $\mathrm{L}_{\text {eff }}$ extraction in submicron fully depleted SOI nMOSFETs at $77 \mathrm{~K}$ is studied both experimentally and by simulation.

\section{EXPERIMENTAL DETARS AND RESULTS}

The SOI nMOSFETs studied were fabricated with drawn channel width $\mathrm{W}_{\mathrm{m}}$ of $20 \mu \mathrm{m}$ and different drawn channel lengths $\mathrm{L}_{\mathrm{m}}$ of $0.7,0.8,0.9,1.0,1.2,1.5,2.0 \mu \mathrm{m}$ in a $0.5 \mu \mathrm{m}$ SOI Technology on SIMOX substrates. The front gate oxide thickness $t_{f o x}$ is $15 \mathrm{~nm}$, the buried oxide thickness tbox is $390 \mathrm{~nm}$, and the silicon film thickness $t_{s i}$ is $100 \mathrm{~nm}$. The $I_{d s}-V_{g s}$ curves were recorded with $V_{d s}=0.1 \mathrm{~V}, V_{g s}$ ranging from -1 to $+3 \mathrm{~V}$ (steps of $0.01 \mathrm{~V}$ ), back gate voltage $V_{\mathrm{gb}}=-5 \mathrm{~V}$ and temperature at $77 \mathrm{~K}$. The $\mathrm{I}_{\mathrm{ds}}-\mathrm{V}_{\mathrm{gs}}$ curves (figure-1) were measured by using an HP $4145 \mathrm{~B}$ parameter analyzer, while the threshold voltage 
$\mathrm{V}_{\text {th }}$ was determined for each transistor by the Linear Extrapolation Method. The effective channel length $L_{\text {eff }}\left(L_{\mathrm{m}}-\Delta L\right)$ was obtained from $I_{d s}-V_{g s}$ curves by using the technique proposed in [2]. Figure-2 shows the corresponding negative value of $\Delta \mathrm{L}$ obtained.

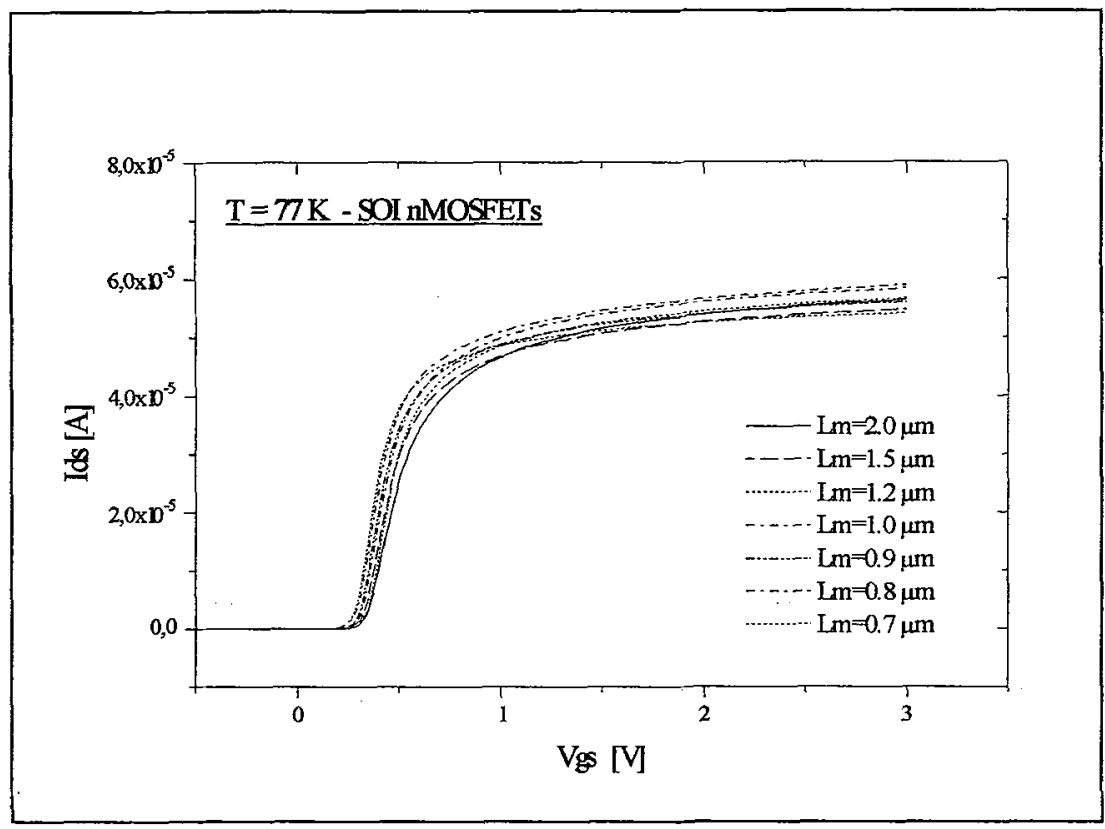

Figure-1: Curves $\mathrm{Ids}_{\mathrm{ds}} \mathrm{V}_{\mathrm{gs}}$ for L-array at $77 \mathrm{~K}$ (experimental).

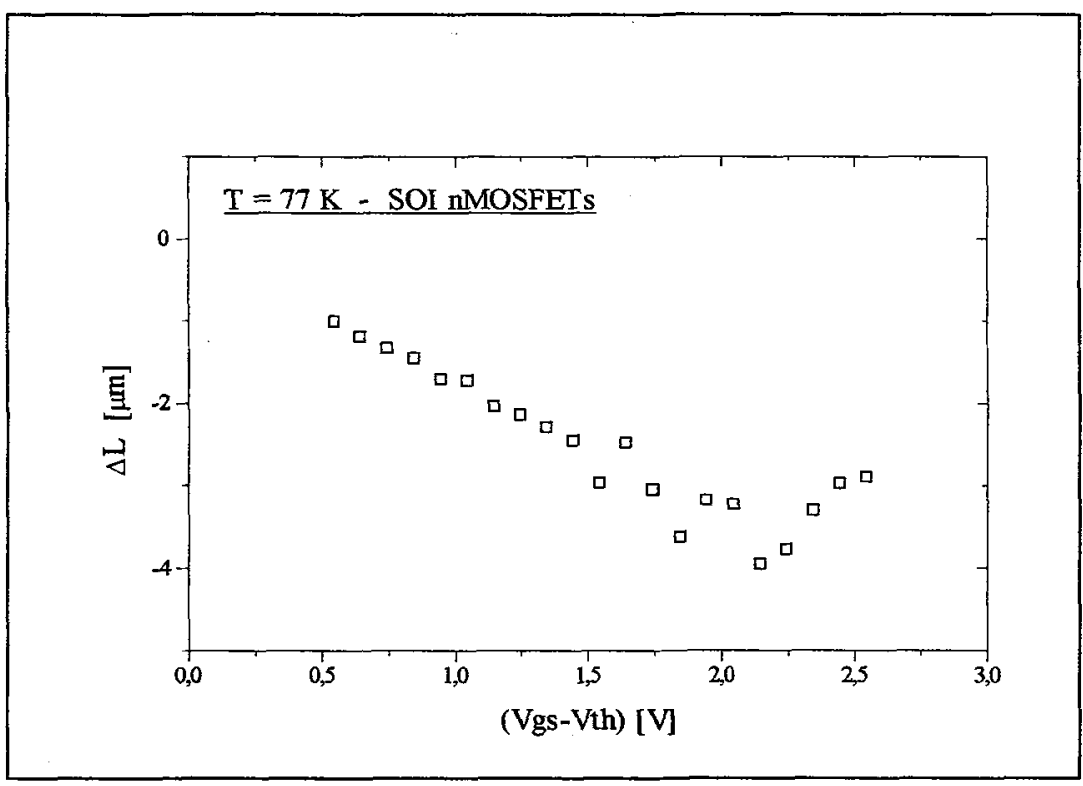

Figure-2: $\triangle \mathrm{L}$ of fully depleted SOI nMOSFETs (experimental) at $77 \mathrm{~K}$ as a function of the gate overdrive voltage. 


\section{SIMULATION RESULTS}

In order to study the influence of the mobility degradation on the $\Delta \mathrm{L}$ extraction, MEDICI [9] simulations are performed of fully depleted SOI nMOSFETs with drawn channel lengths $\mathrm{L}_{\mathrm{m}}$ of $0.8,1.0,1.2,1.4 \mu \mathrm{m}$, $\mathrm{W}_{\mathrm{m}}=20 \mu \mathrm{m}, \mathrm{t}_{\text {fox }}=15 \mathrm{~nm}, \mathrm{t}_{\mathrm{box}}=390 \mathrm{~nm}, \mathrm{t}_{\mathrm{si}}=100 \mathrm{~nm}, \mathrm{~V}_{\mathrm{ds}}=0.1 \mathrm{~V}$, and $\mathrm{V}_{\mathrm{gs}}$ ranging from 0.1 to $2.5 \mathrm{~V}$ (steps of $0.01 \mathrm{~V}$ ). MEDICI includes a model for the perpendicular electric field reduction of effective mobility given by equation (1), where GSURFN is the surface degradation factor, $\mathrm{E} \perp$ is the component of perpendicular electric field, $\mu_{0}$ is the low field mobility (concentration and temperature dependent) and ECN.MU is the critical electrical field.

$$
\mu_{\mathrm{eff}}=\text { GSURFN } \frac{\mu_{\mathrm{o}}}{\sqrt{1+\frac{\mathrm{E} \perp}{\mathrm{ECN} \cdot \mathrm{MU}}}}
$$

As it is known that the surface mobility degradation factor decreases for decreasing gate lengths [10], mainly for low temperatures [8], two simulations were performed: in the first, the surface mobility degradation factor GSURFN was maintained constant (GSURFN $=0.75$ ) for all transistors of the L-array; in the second, the surface mobility degradation factor was varied for each transistor from GSURFN equal 1.0 (longest) to 0.5 (shortest), i. e., for $\mathrm{L}_{\mathrm{m}}$ of $0.8,1.0,1.2,1.4 \mu \mathrm{m}$, the values of the GSURFN were 0.5 , $0.75,0.9,1.0$, respectively. Figure-3 shows the results of $\Delta \mathrm{L}\left(\Delta \mathrm{L}=\mathrm{L}_{\mathrm{m}}-\mathrm{L}_{\text {eff }}\right)$ as a function of the gate overdrive voltage $\left(\mathrm{V}_{\mathrm{gs}}-\mathrm{V}_{\mathrm{th}}\right)$. This figure shows that if a non constant surface mobility degradation factor is used, negative $\Delta \mathrm{L}$ values are obtained and the extraction procedure can not be used.

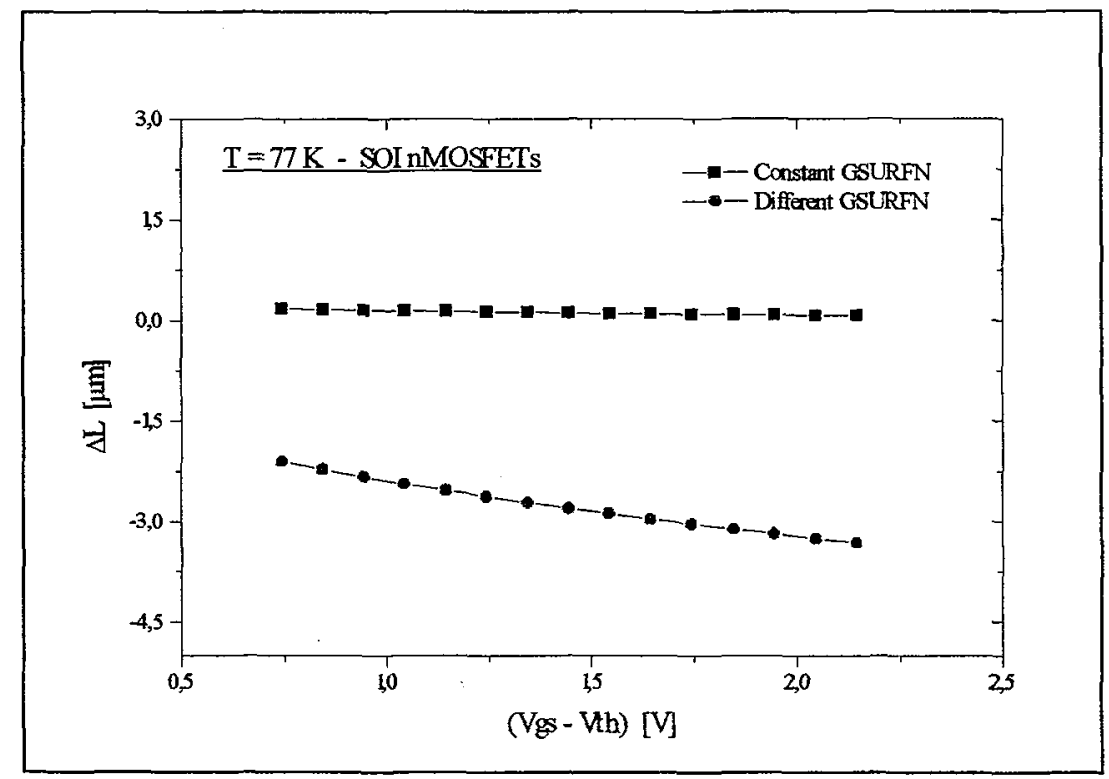

Figure-3: $\triangle \mathrm{L}$ of fully depleted SOI nMOSFETs (simulation) at $77 \mathrm{~K}$ as a function of the gate overdrive voltage and GSURFN. 


\section{DISCUSSION}

The experimental surface mobility degradation factor can be estimated by comparison of the $\mathrm{I}_{\mathrm{ds}}$ curves of the L-array, equation (2), considering the oxide capacitance $\mathrm{C}_{\mathrm{OX}}$ and the effective drawn channel width $\mathrm{W}_{\text {eff }}$ as constant parameters for all transistors of the $\mathrm{L}$-array, negligible threshold voltage changes and a low series resistance. The estimated surface mobility degradation factor (GSURFN) est can be obtained by relation (3), using the longest transistors as a reference, i. e., (GSURFN) ref $=1$, and $\mathrm{L}_{\mathrm{eff}} \approx \mathrm{L}_{\mathrm{m}}$.

$$
\begin{gathered}
\frac{\left(\mathrm{I}_{\mathrm{ds}}\right)_{\mathrm{ref}}}{\left(\mathrm{I}_{\mathrm{ds}}\right)_{\text {est }}}=\frac{\left(\mu_{\text {eff }}\right)_{\text {ref }}\left(\mathrm{L}_{\text {eff }}\right)_{\text {est }}}{\left(\mu_{\text {eff }}\right)_{\text {est }}\left(\mathrm{L}_{\text {eff }}\right)_{\text {ref }}} \\
(\mathrm{GSURFN})_{\text {est }}=\frac{\left(\mathrm{I}_{\mathrm{ds}}\right)_{\mathrm{est}}}{\left(\mathrm{I}_{\mathrm{ds}}\right)_{\mathrm{ref}}} \frac{(\mathrm{GSURFN})_{\mathrm{ref}}\left(\mathrm{L}_{\mathrm{m}}\right)_{\mathrm{est}}}{\left(\mathrm{L}_{\mathrm{m}}\right)_{\mathrm{ref}}}
\end{gathered}
$$

Figure-4 shows the values of (GSURFN) est for transistors of the L-array of figure-1, and it can be seen that the values of the estimated surface mobility degradation factor are not constant. This confirms the hypothesis suggested by simulations.

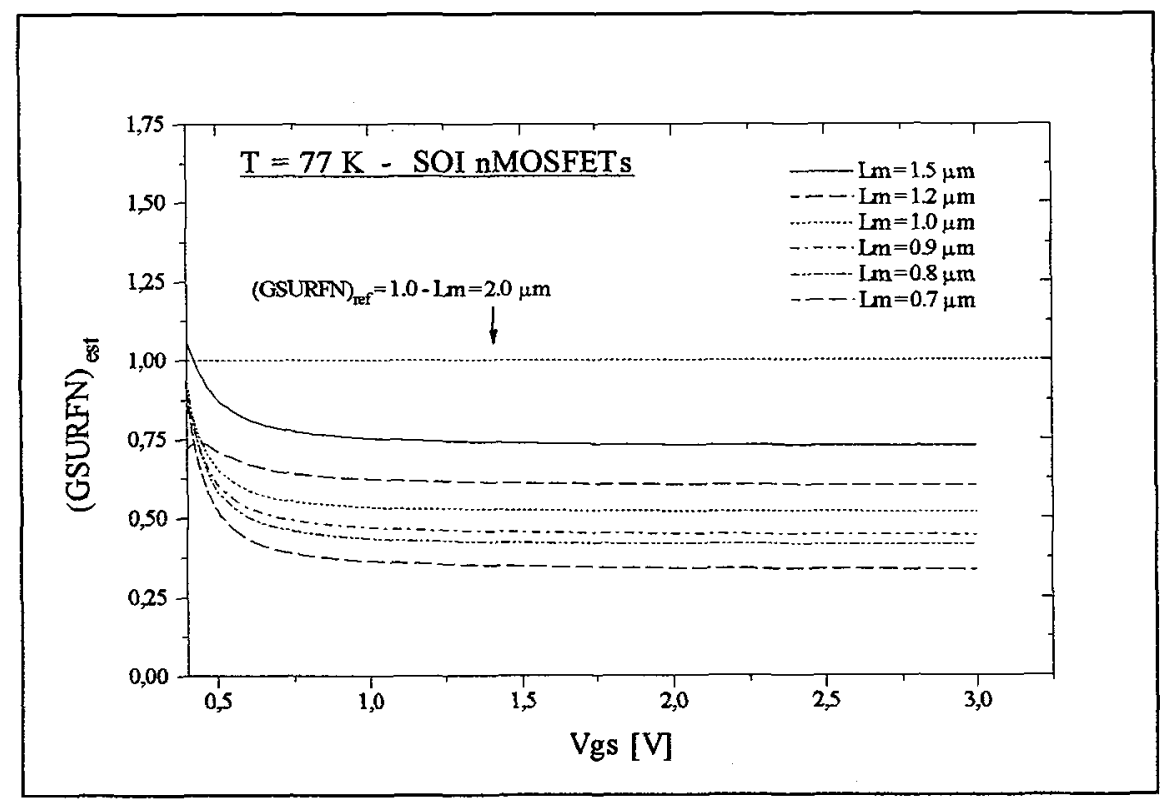

Figure-4: (GSURFN)est (experimental) as a function of the gate voltage. 


\section{CONCLUSION}

It was demonstrated both by simulations and experimentally that negative $\Delta \mathrm{L}$ values can be obtained if the mobility degradation factor changes into each transistor of a same L-array. In this case non of the $\Delta L$ extraction methods can be applied, and a new extraction technique must be developed.

\section{References:}

[1] K. K. Ng and J. R. Brews, IEEE Circuits and Devices Magazine, vol. 6, pp. 33 - 38, November 1990. [2] G. J. Hu, C. Chang and Y. Chia, IEEE Trans. Electron Devices, vol. ED-34, pp. 2469-2475, December 1987.

[3] J. Guo, S. S. Chung and C. C. Hsu, IEEE Trans. on Electron Devices, vol. 41, pp. 1811-1818, October 1994.

[4] Z. P. Zuo, M. J. Deen and J. Wang, "A new method for extracting short-channel length or narrowchannel width MOSFET linear parameters." Canadian Conference on Electrical and Computer Engineering, Montreal, PQ, Canada, 17-20 September 1989.

[5] Y. El-Mansy, IEEE Transactions on Electron Devices, vol. 29, pp. 567-573, April 1982.

[6] J. P. Colinge, Silicon-on-insulator technology: materials to VLSI (Kluwer Academic Publishers, 1991), pp. 120-123.

[7] E. Takeda and N. Suzuki, IEEE Electron Devices Letters, vol. 4, pp. 111-113, April 1983.

[8] C. H. Duc, S. Cristoloveanu and G. Ghibaudo, Solid State Electronics, vol. 29, no. 12, pp. 1271-1277, 1986.

[9] TMA MEDICI: Two-Dimensional Device Simulation Program, version 2.1.2, Technology Modeling Associates Inc., Palo Alto, CA1995.

[10] J. I. Lee, M. B. Lee and K. N. Kang, "Mobility Reduction Parameters in Short-Channel MOSFETs.", Electronics Letters, vol. 25, no. 11, pp. 753 - 754, 1989. 